\title{
Evidence for prospect-refuge theory: a meta-analysis of the findings of environmental preference research
}

\author{
Annemarie S. Dosen ${ }^{*}$ and Michael J. Ostwald
}

\begin{abstract}
Background: Researchers in the field of spatial psychology and environmental preference theory have tested a range of claims about the capacity of certain spatial configurations to evoke a positive sense of wellbeing in observers. In parallel, across the landscape, urban, architectural and interior design disciplines, there has been a growing acceptance that a balance of spatial characteristics -including prospect, refuge, mystery and complexity -is desirable in a natural, urban or interior environment. Yet, the evidence that the design disciplines cite for the desirability of these characteristics is often entirely qualitative and only rarely acknowledges the results from the fields of spatial psychology and environmental preference theory.

Methods: The purpose of this paper is to provide a critical overview of the results of quantitative research which has been undertaken into the veracity of prospect-refuge theory and closely associated aspects of environmental preference theory. This meta-analysis not only involves a review of the results, but also their broad classification to develop a more holistic picture of the field, its findings and any gaps. The purpose of this process is not, explicitly at least, to assess the believability or rigour of this past research, but rather to examine and classify the findings, both for and against prospect-refuge theory, in a way that is useful for the design disciplines.
\end{abstract}

Results: Urban and interior studies supported the significance of prospect, and were more neutral about refuge. Studies related to natural environments provided evidence for the significance of both prospect and refuge, which has been linked to comfort, but also included evidence against and a neutral finding. More specifically for designers, the results for complexity seem to confirm that a degree of complexity in interior space is preferred, but they are unclear about how much or where it should be. The results for mystery are less emphatic with the majority being neutral or contrary.

Discussion and Conclusions: The quantitative evidence for prospect-refuge theory remains inconsistent. It is especially problematic that the results which are most commonly cited in architecture relate to studies of natural environments, not interiors or urban environments. As this paper demonstrates, the results are most valid in specific venues.

Keywords: Design assessment, Environmental preference, Prospect-refuge theory

\section{Background}

In the modern world, designers and planning authorities are responsible for creating and approving new spaces that contribute to a pleasant, healthy and sustainable environment. As such, policies, standards and procedures for architectural, urban and landscape designers

*Correspondence: Annemarie.Dosen@newcastle.edu.au

The University of Newcastle, Callaghan, NSW, Australia increasingly anticipate the use of approaches which have a positive impact on human perceptions and behaviour (Shaftoe 2008; Gutman 2009). Such expectations have, since the 1970s, been driving an increased practical interest in explaining or predicting human responses to space and form (Perloff 2015). Indeed, theories about the way in which people perceive and respond to the spaces they inhabit can be found in the oldest architectural treatises and the earliest utopian works (Kruft 1994). Not 
surprisingly then, the concept that a particular combination of space, form and context might have a positive effect on a person's emotional state is often raised in the design disciplines (Menin 2003; Crankshaw 2008) and it has even found its way into various guidelines and primers (Lidwell et al. 2003; Lippmann 2010).

Probably the most known theory for explaining environmental preference in the architectural, interior and urban design disciplines is 'prospect-refuge theory', although its application in design actually combines aspects of Berlyne's (1951) 'arousal theory' and Kaplan and Kaplan's (1989) 'information model' with Appleton (1975) prospect-refuge theory. The merging of these different theories, along with several additional themes, was proposed by Grant Hildebrand (1991), an architectural historian attempting to explain the innate appeal of several of Frank Lloyd Wright's residences. Hildebrand's (1991, 1999) research combined several different explanations of human perceptions and emotions to propose a formula for creating an ideal environment.

In the last two decades this expanded variation of prospect-refuge theory has seemingly become accepted in the design disciplines as offering an explanation of basic human responses to the environment, and as a type of guideline for creating ideal spaces (Kellert 2005; Lippmann 2010). However, Hildebrand's argument is entirely qualitative, as too is Appleton's, which is also, despite the way it is cited in architecture, about preferences for landscape views. Nevertheless, architectural applications of this theory are allegedly seen in the works of renowned designers including Alvar Aalto and Pritzker prize winners Glenn Murcutt, Jørn Utzon and Peter Zumthor (Gallagher 2007). But once again, the evidence for these claims is qualitative and circumstantial. Indeed, arguments for the efficacy of prospect-refuge theory in design only rarely identify specific quantitative or empirical studies to support their claims. This situation is the catalyst for the present paper, which revisits the key quantitative evidence that is available for prospect-refuge theory (and its associated theories) to collectively assess their findings and relevance to the design of landscapes, cities, buildings and interiors.

Originally, developed by Appleton (1975) for explaining preferences for certain landscapes, prospect-refuge theory argues that we derive feelings of safety and pleasure from inhabiting environments that offer both views and a sense of enclosure. This appeal is arguably universal and subconsciously influences our day-to-day decisionmaking (Ellard 2009). The central assumptions of prospect-refuge theory can be connected to both Darwinian nineteenth century anthropological beliefs about survival instincts as well as to phenomenological studies that examine environments in relation to the human body
(Husserl 1973). Prospect-refuge theory also has parallels with arousal theory, which suggests that an increase of pleasure is felt when a person views a space or scene that has a degree of uncertainty or novelty about it, but if uncertainty is increased beyond that point, feelings of anxiety begin to occur (Berlyne 1951).

In architecture and design, Hildebrand (1991, 1999) expanded the standard definition of prospect-refuge theory to include four additional spatio-cognitive elements: mystery, complexity, enticement and illumination. Most of these can be traced to Kaplan and Kaplan's (1989) information theory framework which suggests that environments that provide increased opportunities for gathering or discovering information allow for improved living conditions including heightened safety. Thus various spatio-cognitive properties associated with exploration potential (including complexity and mystery) also have an impact on environmental preference.

As a result of the work of Hildebrand (1991), a growing number of architectural critics and historians have used an expanded definition of prospect-refuge theory to justify or analyse architectural spaces in terms of psychological wellbeing (Jacobsen et al. 2002; Roberts 2003; Gallagher 2007; Unwin 2010). The resultant model of a preferred environment has four components. First, a space must have a view or outlook, and second, that view must be at least partially framed or enclosed. Third, a degree of visual complexity enhances feelings of safety and finally, a sense of mystery (implying discoverability or directionality) is preferred (Dosen and Ostwald 2013a).

Despite this apparent agreement between researchers, the capacity to understand and shape human perceptions of environments is actually a more complex and vexed topic. For example, the way people perceive environments is clearly different depending on their physical stature and size or the personal experiences (Wohlwill 1976; Heerwagen 1998). Despite this, architectural and design texts tend to selectively emphasise the universal aspects of spatial experience (Kellert 2005; Lippmann 2010). This may not be entirely unreasonable because people do experience aspects of space, including its organisation, in similar ways (Ellard 2009). For example, quantitative studies have shown that a close visual connection between habitable space and nature is beneficial for psychological wellbeing, recovery and stress relief (Kaplan and Kaplan 1989; Heerwagen and Orians 1993). Studies have also observed that restricted views may cause negative reactions (Heerwagen 2008) while visual connections might encourage movement and evoke pleasure through the exploration of space (Kaplan 1987). There is evidence that people have a preference for spaces which feature access to nature and daylight (Ulrich 1993) and for surroundings that support social interaction and 
thereby create safer environments (Kuo and Sullivan 2001; Ellard 2015). In addition, a preference for water views, which are perceived as calming, is often noted in studies (Ulrich 1984; Kaplan and Kaplan 1989; Heerwagen and Orians 1993). However, Stamps (2006, 2008a, b) examined ratings for comfort and preference for both natural and built environments and concluded that the statistical significance of prospect, refuge and luminosity factors, in shaping emotional response, was 'very near zero' (Stamps 2008b, p 141). Indeed, the only factor which Stamps found had any evidence of shaping environmental preference was 'venue', being the particular type of environment where the studies were undertaken. Stamps' findings emphasise the fact that the evidence for environmental preference theory, and especially as it relates to different types of designed environments-the urban, architectural and interior-is more complex than it seems.

The present paper summarises and classifies the results of thirty-four studies that have used quantitative means (generally data derived from surveys, interviews or computational and mathematical analysis) to examine the veracity of four specific spatio-cognitive factors-prospect, refuge, mystery and complexity-as part of spatial preference theory in design. The first two of these factors are the most commonly tested, as they were the earliest proposed by Appleton (1975), while research into the latter pair is less common, and is often associated with Hildebrand's $(1991,1999)$ identification of them as being equally significant in architecture and design. Importantly, this paper does not undertake a detailed review of the methods that have been used to test these factors, as the majority have already been examined from a methodological perspective (Dosen and Ostwald 2013b). Instead, the results of the thirtyfour studies are each classified in terms of whether their findings support the efficacy of each of the four factors, or are neutral, or contrary in terms of their role shaping environmental preference.

In addition, to reviewing the results of the thirtyfour studies holistically, they are also divided into three groups in accordance with their specific focus or venue of testing. The three groups are: urban studies (9\%), territorial studies (29\%), and architectural studies (62\%). This division by venue or focus is significant as it assists in differentiating which evidence can most reasonably be used to support arguments about interiors, cities and landscapes. Furthermore, while findings associated with the four specific factors-prospect, refuge, mystery and complexity-will be collectively considered in the conclusion, many results are specific to the environment or venue they were tested in. For example, the ratings for prospect and refuge conditions can be heavily influenced by concerns about safety when being exposed in a natural or urban environment, while this is less of a concern when being inside a building. Thus, the results of the various studies analysed here are often valid in a particular context, but not necessarily in any other.

\section{Methods}

The thirty-four quantitative studies chosen for this metaanalysis comprise the full set of works that fulfil five criteria. First, they have a focus on testing at least one of the following environmental characteristics: prospect, refuge, mystery and/or complexity. Second, these studies use quantitative methods. Third, they are readily accessible, meaning they are either published or available through databases. Fourth, they are cited in the architecture and design literature as evidence for the efficacy of the four perceptual properties, or use keywords that are directly linked to these properties. Finally, all of the studies offer some conclusions, based on the evidence they have collected, about the validity of the factor or factors being considered. Importantly, for each of these thirty-four studies only their findings are compared in this paper, not their methods. Furthermore, no direct commentary is provided here about the statistical rigour or empirical validity of their results, although in all cases it could be said that the results appear reasonable, given the methods used and their stated or otherwise obvious practical limitations. Nevertheless, the paper does examine some of the demographic information which is recorded in past research to assist with interpreting the findings and directions for future research.

Because environmental preference theory combines both spatial and psychological properties, the thirtyfour studies include those focussed largely on perceptual properties (twenty studies), those focussed on geometric properties (five studies) and those which combine the two (nine studies). The perceptual properties are generally tested using surveys whereas all but one of the geometric studies use isovist analysis. For this reason, it is useful to define each of the four major properties which are compared in the present paper in both perceptual and geometric terms. First, prospect is associated with the perceptual properties of outlook, depth of view, spaciousness and openness, and the geometric properties of isovist area and maximum radial line length. Second, refuge is associated with the perceptual properties of enclosure and safety, and the spatio-visual geometry of occlusion and minimum radial length. Mystery relates to transitions between spaces, to changing luminosity and the degree of occlusivity. Complexity refers to the volume of information present in a space, along with the number of occluding edges (or vertices) and the jaggedness of its geometry. 
When assessing the thirty-four studies, all were initially classified in three ways-supportive, neutral and contrary-in respect of claims about preferences for prospect, refuge, mystery and complexity. In general, findings directly relating to these spatio-cognitive properties were accepted prima-facie. That is, the author's conclusions were accepted in the majority of cases. However, where a study only indirectly tested one of the spatio-cognitive properties, it was classified in accordance with the pertinent section of the data. For example, if the primary purpose of the study was to determine if men and women have similar spatial perceptions and its secondary purpose was to see if they have similar tastes, then the result of the gender differentiation part of the test was ignored in our classification.

Findings that confirmed the basic assumptions of the expanded variation of prospect-refuge theory were classified as 'supportive' (indicated with a ' $\sqrt{ }$ ' in the tables). However, it is important to remember that not all positive findings of this type were equally emphatic and, as the tabulated summaries and quotes reveal, many were only partially supportive. Neutral findings (indicated with a ' $\mathrm{O}$ ' in the tables) are ones wherein the evidence is either not statistically significant, or it is only pertinent to testing a meta-principal, like the consistency of an argument or of a spatial property. In the former case, partially supportive findings were categorised in the neutral group if they relied on less than $66 \%$ of the data or equivalent confidence indicators. In the latter case, many of the neutral studies used computational or mathematical approaches to test the presence or absence of a claimed prospect-refuge pattern in spatial data. Thus, some of these computational studies may confirm the presence of a pattern, but if it does not clearly conform to the expectations of prospect-refuge theory, it is classed as neutral here. Contrary findings (indicated with a ' $\mathrm{X}$ ' in the tables) are examples of the failure to find evidence to support the impact of one of the factors, or of clear evidence against the significance of one or more factors.

\section{Results}

\section{Environmental preference in urban settings}

Only three of the studies were specifically focussed on urban environments (Table 1). One of these proposes that a balanced feeling of prospect and refuge is rated as safer than either one or the other (Loewen et al. 1993). However, another urban study failed to confirm the relationship between the two criteria as it found that only refuge presents a strong correlation with safety as well as comfort, while prospect has a positive correlation with attractive scenes (Mumcu et al. 2010). Nasar's (1988) findings are relatively neutral and show a clear preference for environments that are interesting rather than bland, a factor which might seem to have a bearing on perceptions of complexity. However, a preference for ordered environments or for more visually contrasting settings was seen to be dependent on the cultural background of the participants. Ultimately, the urban studies supported the significance of prospect, and were more neutral about the other factors (Fig. 1).

\section{Findings relating to environmental preference in landscapes}

Appleton (1975) explains the existence of a preference for natural environments as an innate characteristic of humankind, which can also be affected by social, historical and cultural influences. Many quantitative studies refer to this general human preference for natural settings (Kaplan and Kaplan 1989; Heerwagen 2008) and some specific studies, that involve children as participants, also confirm a preference for a natural rather than built environments (Nettleton 1987; Conrad 1993). However, across the ten studies included in this category, six found evidence for the significance of prospect and five for refuge, a result that is typically linked to perceptions of comfort (Table 2). According to Ruddell and Hammitt (1987) an immediate refuge is most preferred while prospect dominance is least preferred. Conrad's (1993) multiple experiments indicate a preference for prospect-refuge balanced scenes, whereas Hagerhall's (2000) data demonstrates a connection between preference, exploration potential (mystery) and feelings of safety (refuge). Stamps (2008a, b) is the only one who presents contrary results. In one of his studies ambiguous results are presented for refuge wherein "[n]atural scenes with no occluding edges were the least preferred, but built scenes with no occluding edges were the most preferred" (Stamps 2008a, p 159); also "the overall effect of refuge on responses of comfort was small" (Stamps 2008a, p 161). Nature views were generally preferred over views on the built environment; short views of the built environment (looking at small shops) were preferred over distant views (of large malls) while for natural environments the depth of view (or degree of prospect) did not influence preference ratings (Stamps 2008b). Stamps explains this result as arising from the chosen background images and suggests that varying backdrops may skew objective ratings. In total in this category, there were five contrary findings, and only three neutral, although nearly all of the tests were concerned with prospect and/or refuge, only three with mystery and none examined complexity (Fig. 2).

\section{Environmental preference in interiors}

There are twenty-one studies in this category associated with environmental preference and interior space. Seven of the studies rely on surveys, five use computational 
Table 1 Findings relating to environmental preference in urban settings

\begin{tabular}{|c|c|c|c|c|c|}
\hline Urban settings & $\mathbf{P}$ & $\mathbf{R}$ & $M$ & C & Findings \\
\hline $\begin{array}{l}\text { Nasar (1988) } \\
\text { Survey using stimuli }\end{array}$ & $\sqrt{ }$ & - & - & $\mathrm{O}$ & $\begin{array}{l}\text { Relatively neutral findings: both, Japanese and US students show highly correlated results } \\
\text { for their ratings for pleasantness and interestingness. "Increases in preference for scenes } \\
\text { were found to be related to increases in [... n naturalness, absence of vehicles, and } \\
\text { scene-order" (269). Some factors depend on cultural influence, for example, Japanese } \\
\text { students prefer organisation and contrast }\end{array}$ \\
\hline $\begin{array}{l}\text { Loewen et al. (1993) } \\
\text { Survey using stimuli }\end{array}$ & $\sqrt{ }$ & $\mathrm{O}$ & $\mathrm{O}$ & - & $\begin{array}{l}\text { Positive and neutral findings: light was rated as most important single variable for safety; } \\
\text { prospect (open space) more important than refuge, and the "combination of the three } \\
\text { features was rated as safest" (330) }\end{array}$ \\
\hline $\begin{array}{l}\text { Mumcu et al. (2010) } \\
\text { Survey in situ }\end{array}$ & $\sqrt{ }$ & $\sqrt{ }$ & - & - & $\begin{array}{l}\text { Positive findings: "prospect has shown a strong and positive correlation with attractive } \\
\text { scene [...]. Refuge has had a strong correlation with sense of safety [...] and a cor- } \\
\text { relation with comfort" (1230). However, there was no significant relation between "the } \\
\text { preferred areas and the areas determined for refuge, comfort and safety" (1230) }\end{array}$ \\
\hline Supportive $\sqrt{ }$ & 3 & 1 & 0 & 0 & \\
\hline Neutral O & 0 & 1 & 1 & 1 & \\
\hline Contrary X & 0 & 0 & 0 & 0 & \\
\hline
\end{tabular}

$\sqrt{ }$ supportive, $O$ neutral, $X$ contrary, - not considered in the study, $P$ prospect, $R$ refuge, $M$ mystery, $C$ complexity

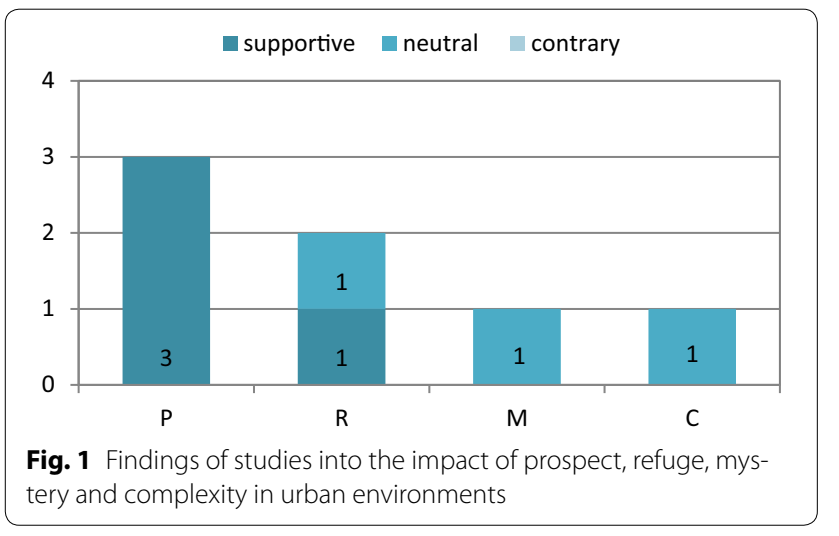

simulations of environmental geometry, and nine use a combined approach drawing on both methods (Table 3). A total of nineteen of the studies consider prospect or spaciousness with ten confirming that it is a critical spatial property shaping preference while another eight were more neutral. In several of the positive cases, people rated views from the interior to nature or to adjacent spaces as being preferred over a lack of views or of being tightly enclosed in space. Only one of the studies examined views from both interior and from exterior observation points with varying backdrops and found contrary results for prospect (Stamps 2008b) (Fig. 3).

Several of the isovist-based computational studies developed evidence which offered only a low level of support for prospect-refuge theory, or were more concerned with secondary evidence pertaining to the buildings used by Hildebrand to develop his argument. For example, Dawes and Ostwald (2014a) examined five of Frank Lloyd Wright's textile-block houses in terms of their spatial properties as understood in relation to prospect and refuge characteristics. They did this over several stages: first considering the spaces individually (in terms of area, height and radial length) and then as a paired, by measuring their degree of "reduplication" which is represented by the Pearson's correlation coefficient for each combination of prospect and refuge indicators (238). According to Hildebrand (1999) multiple prospect and refuge indicators operate together to enhance Wright's pattern. However, not all indicators recorded by Dawes and Ostwald (2014a) confirm this claim. The strongest, positive correlations were found between height and minimum radial length as well as between height and area.

Altogether fifteen studies examined refuge in interiors, mostly with relatively neutral findings. Some of these studies presented a combined approach using computational analysis and survey methods to ask, for example, people to identify the smallest area (or best place to hide), and then compare this rating with the smallest isovist area (refuge). Only two studies confirmed a need for partial enclosure (Scott 1993a; Stamps 2008b), while another two studies presented contrary results. One of these confirms a preference for large rooms and substantiates (in a second test) width as the main criterion for comfort (Stamps 2006). The other test confirms that a "wideopen view was more comforting than the view over the fence" contrary to prospect-refuge theory (Stamps 2008b, p 153). Further relatively neutral measurements or evidence for prospect-refuge theory included those derived from isovist area (prospect and refuge) and minimum radial line (as an indicator of refuge) (Dawes and Ostwald 2014a, c).

Studies of environmental preference in interior settings include the largest percentage examining mystery and complexity. Only twelve studies included in the scope of the present paper consider mystery, of which eight are concerned with interiors. Two of Scott's studies present 
Table 2 Findings relating to environmental preference in landscapes

\begin{tabular}{|c|c|c|c|c|c|}
\hline Landscapes & $\mathbf{P}$ & $\mathbf{R}$ & $M$ & $C$ & Findings \\
\hline $\begin{array}{l}\text { Nasar et al. (1983) } \\
\text { Survey in situ }\end{array}$ & $\sqrt{ }$ & $\mathrm{O}$ & - & - & $\begin{array}{l}\text { Positive and neutral findings: "in agreement with Appleton (1975), the open view was } \\
\text { judged as safer than the closed one, and this effect was more pronounced from an } \\
\text { open observation point than from a protected one. However, in contrast to Appleton } \\
\text { (1975), this effect did not carry over to environmental preference, and males (unlike } \\
\text { females) liked the setting with less refuge." (361) }\end{array}$ \\
\hline $\begin{array}{l}\text { Ruddell and Hammitt (1987) } \\
\text { Survey using stimuli }\end{array}$ & $\sqrt{ }$ & $\sqrt{ }$ & - & - & $\begin{array}{l}\text { Positive findings: "the refuge symbolic (immediate) edge environment was the most } \\
\text { preferred [...] refuge symbolic (distant) was the second most preferred }[\ldots \text { and t] he } \\
\text { third most preferred }[\ldots] \text { was the refuge dominant }[\ldots] \text {. The least preferred }[\ldots] \text { was the } \\
\text { prospect dominant }[\ldots] . \text {. (255) }\end{array}$ \\
\hline $\begin{array}{l}\text { Kaplan and Herbert (1988) } \\
\text { Survey using stimuli }\end{array}$ & $\mathrm{O}$ & - & - & - & $\begin{array}{l}\text { Neutral findings: "reflecting a relatively low preference for [...] rural residences viewed in } \\
\text { the context of otherwise more natural scenes" (382) as well as an "increased preference } \\
\text { for more novel settings and decreased preference for seemingly familiar settings" (388) }\end{array}$ \\
\hline $\begin{array}{l}\text { Conrad (1993) (test 1) } \\
\text { Survey using stimuli }\end{array}$ & $\sqrt{ }$ & $\sqrt{ }$ & - & - & $\begin{array}{l}\text { Positive findings: "there was no significant difference between trained and untrained } \\
\text { observers" in recognising pleasant or unpleasant stimuli (141). "[T] } \text { he prospect [domi- } \\
\text { nant] pictures were considered the most unpleasant followed by the refuge pictures. } \\
\text { The balanced pictures were rated as most pleasant" (164) }\end{array}$ \\
\hline $\begin{array}{l}\text { Conrad (1993) (test 2) } \\
\text { Survey using stimuli }\end{array}$ & $\sqrt{ }$ & $\sqrt{ }$ & - & - & $\begin{array}{l}\text { Positive findings: "landscape settings that are highly prospect are considered least } \\
\text { pleasant, those that are highly refuge more pleasant, while prospect/refuge balanced } \\
\text { settings are considered the most pleasant" (175) }\end{array}$ \\
\hline $\begin{array}{l}\text { Conrad (1993) (test 3) } \\
\text { Survey using stimuli }\end{array}$ & $\sqrt{ }$ & $\sqrt{ }$ & - & - & $\begin{array}{l}\text { Positive findings: "eleven out of the twelve pictures created [by children] are clearly } \\
\text { prospect/refuge balanced" (185) }\end{array}$ \\
\hline $\begin{array}{l}\text { Hagerhall (2000) } \\
\text { Survey using stimuli }\end{array}$ & $\sqrt{ }$ & $\sqrt{ }$ & $\sqrt{ }$ & - & $\begin{array}{l}\text { Positive findings: "preference is related to whether or not the landscape is interesting to } \\
\text { explore and to a feeling of security" (89) }\end{array}$ \\
\hline $\begin{array}{l}\text { Stamps (2008a) (test 1) } \\
\text { Survey using stimuli }\end{array}$ & - & $x$ & $x$ & - & $\begin{array}{l}\text { Contrary findings: "the dominant source of comfort [...] was venue. The view of the lake } \\
\text { was judged as being most comfortable; the view of the glacier was judged as being } \\
\text { least comfortable. [...] Effects of refuge, represented as permeable regions in the } \\
\text { foreground of the view, and direction of light, were nil" (155) }\end{array}$ \\
\hline $\begin{array}{l}\text { Stamps (2008a) (test 2) } \\
\text { Survey using stimuli }\end{array}$ & $\mathrm{O}$ & $X$ & - & - & $\begin{array}{l}\text { Neutral and contrary findings: "natural scenes with no occluding edges were the least } \\
\text { preferred, but built scenes with no occluding edges were the most preferred. [...] } \\
\text { For nature scenes, the scenes with the longest depth of view were preferred over the } \\
\text { scenes with the closest depth of view [...] while for the rooms [...] the scene had a } \\
\text { very small effect on preference" (159). Refuge was supported for natural backdrops only } \\
\text { (not for built environments) }\end{array}$ \\
\hline $\begin{array}{l}\text { Stamps (2008b) (test 1)b } \\
\text { Survey using stimuli }\end{array}$ & $X$ & - & $X$ & - & $\begin{array}{l}\text { Contrary findings: "natural environments being judged as more comfortable than built } \\
\text { environments [...] The effect for light was tiny [...] The effect for depth of view did not } \\
\text { support the hypothesis that increased prospect causes increased comfort" (146) }\end{array}$ \\
\hline Supportive $\sqrt{ }$ & 6 & 5 & 1 & 0 & \\
\hline Neutral O & 2 & 1 & 0 & 0 & \\
\hline Contrary X & 1 & 2 & 2 & 0 & \\
\hline
\end{tabular}

$\sqrt{ }$ supportive, $O$ neutral, $X$ contrary, - not considered in the study, $P$ prospect, $R$ refuge, $M$ mystery, $C$ complexity

a Views on nature

b Views on nature and built environment

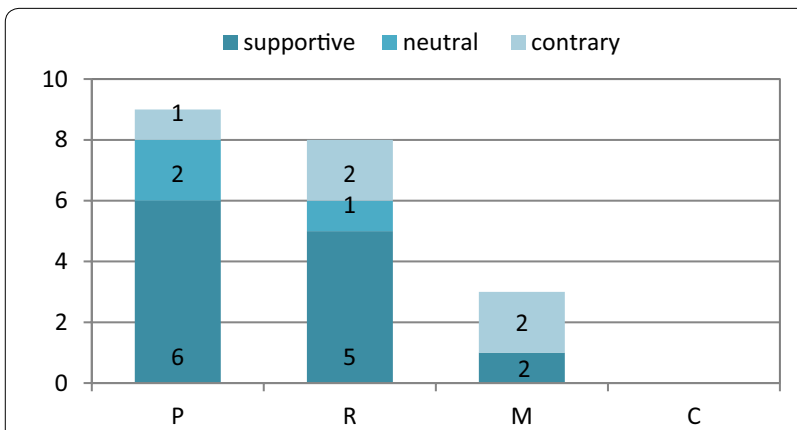

Fig. 2 Findings of studies into the impact of prospect, refuge and mystery in landscapes findings for a preference for "interiors [...] that imply that there is more to the environment that can be experienced from the observer's present vantage point" (Scott 1993b, p 31). One of Stamps' (2006) tests presents findings contrary to the hypothesis that views from small to large rooms would be rated as more comfortable as "views from large, bright, high rooms were judged as being considerably more comfortable" (Stamps 2006, p 649). In addition, Ostwald and Dawes (2013) present a contrary finding for mystery as only two of the five examined Frank Lloyd Wright's Prairie houses confirm the anticipated pattern. Four other studies have been categorised as neutral as they are only marginal supportive. 
Table 3 Findings relating to environmental preference in interiors

\begin{tabular}{llllll}
\hline Interiors & P & R & M & C & Pin \\
\hline $\begin{array}{l}\text { Scott (1993a) } \\
\text { Survey using stimuli }\end{array}$ & $\sqrt{ }$ & $\sqrt{ }$ & $\sqrt{ }$ & $\sqrt{ }$ & \\
& & & & & \\
Scott (1993b) & & & & & \\
Survey using stimuli & - & - & $\sqrt{ }$ & $\sqrt{ }$ &
\end{tabular}

\section{Findings}

Positive findings: the study revealed a preference for "horizontally and vertically spacious settings structured into multiple, partially enclosed zones that permit visual access from one area to another; more rather than less complexity [...], and natural content in the form of plants, window views, natural light and soft forms" (15)

Survey using stimuli

Positive findings: complexity (high) and mystery (moderately high) are positive correlated to preference and to each other. "Scenes that offered greater depth and included views of destinations more immediate [...] were perceived as offering more mystery" (29). "[B]oth the tightest [...] and the most wide-open spaces were perceived as having little mystery" (30)

Franz et al. (2003)

Combined survey and isovists

Franz et al. (2004) (test 1)

Combined survey and isovists

Franz et al. (2004) (test 2)

Combined survey and isovists

Stamps (2006) (test 1)

Survey using stimuli

Stamps (2006) (test 2)

Survey using stimuli

Wiener et al. (2007) (test 1)

Combined survey and isovists

Wiener et al. (2007) (test 2)

Combined survey and isovists

Wiener et al. (2007) (test 3)

Combined survey and isovists

Stamps (2008b) (test 2) ${ }^{a}$

Survey using stimuli

Stamps (2008b) (test 3) ${ }^{\mathrm{b}}$

Survey using stimuli

Stamps (2008b) (test 4) ${ }^{\mathrm{b}}$

Survey using stimuli

Dalton et al. (2010)

Combined survey and isovists $\sqrt{ } \quad \mathrm{O}-$

Positive and neutral findings: "spaciousness correlated with the actual room area [...] but the coefficient with overall window area was even higher [... and] the correlation [of the three evaluative rating dimensions beauty, pleasure and interestingness] with the physical openness ratio was highest" (6)

Positive and neutral findings: "isovist area as the dominant factor [...] highly correlated with all rating categories [...] except for clarity" (7)

$\sqrt{ } \quad \mathrm{O} \quad-\quad \sqrt{ } \quad$ Positive and neutral findings: "rated spaciousness [...] and beauty were [...] strongly correlated with isovist area [... and] complexity was correlated highest with the number of vertices" (7)

$\sqrt{ } \quad X \quad \mathrm{O} \quad$ - $\quad$ Mixed findings: "the main finding was that nothing showed up [...] [l]t made very little difference if one were looking from the small, dark. Low room into the large, light, tall room or vice versa [...] The individual contrasts for differences in light [...] and differences in height [...] were also very small [...] The only contrast that had a more than trivial effect was the difference between looking from a large room into a small room [...], and that contrast was opposite to the relevant hypothesis" (647)

$\sqrt{ } \quad X \quad X \quad-\quad$ Mixed findings: "views from large, bright, high rooms were judged as being considerably more comfortable [...] views from the large rooms were more comfortable" (649). "For light, the difference between dark to light and light to dark was small [...] the prediction that views from wide rooms would be more comfortable than views from narrow rooms was supported by the data" (651)

$\sqrt{ } \quad \mathrm{O} \quad-\quad \sqrt{ } \quad$ Positive and neutral findings: "while performance of female and male subjects did not differ with respect to finding the best overview place [...] male subjects showed a better performance in finding the best hiding place than female subjects" (1074). "Average isovist area was highly correlated with rated pleasingness [...], beauty [...] and spaciousness [... and] the average number of isovist polygon vertices [...] turned out to be strongly interrelated with experienced complexity [...], interestingness [...] and clarity" (1075)

$\sqrt{ } \quad \mathrm{O}-\sqrt{ }$

Positive and neutral findings: "no significant differences were found between the mean ratings of the two experiments [...] scenes perceived as more interesting in experiment 2" (1077)

$\mathrm{O} \quad \mathrm{O}-\mathrm{O}$

Neutral findings: male better in finding best overview place. "[J]aggedness was negatively correlated with average angular velocity during locomotion, i.e. subjects turned more slowly in more complex environments" (1080)

$\mathrm{O}-\quad-$

Neutral findings: "rooms with nature views being perceived as being more comfortable than rooms with views of shops" (149). "Depth of view made little differences for the nature scenes [...] but depth of view made substantial differences for the built scenes [.,I] with shorter depths of view [on small shops] being preferred over longer [on mall]" (150)

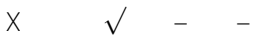

Mixed findings: "the more refuge, the greater the comfort [...]. The relationship to prospect was sufficiently weak to be nonsignificant over the range of 20-60 m. For the range of 60-80 m, the relationship of comfort to prospect was opposite the prediction of prospect and refuge theory, with the closer tree line $(60 \mathrm{~m})$ being judged as more comfortable than the farther tree line $(80 \mathrm{~m})^{\prime \prime}(152)$. Supportive of refuge, not prospect. (Participants: men only.)

$\sqrt{ } \quad \times \quad-\quad-$

Mixed findings: "For refuge there was a significant relationship for comfort between the no-refuge and the fence conditions [...] but in direction opposite to theory. These respondents felt [that] the wide-open view was more comforting than the view over the fence" (153). (Same test as under c but with men and women)

$\mathrm{O} \quad \mathrm{O}-\mathrm{O}$

Neutral findings: "stimuli materials were [...] equally well recognised if they were displayed in a location visible from a large or a small isovist [... but] for the large isovist areas, images were recognised better than words [...] whereas for the small isovist areas, words were recognised better than images [... and] images were recognised significantly better in spiky [more complex/low isovist area to perimeter ratio] than in round spaces" (3844) 
Table 3 continued

\begin{tabular}{|c|c|c|c|c|c|}
\hline Interiors & $\mathbf{P}$ & $\mathbf{R}$ & $M$ & $C$ & Findings \\
\hline $\begin{array}{l}\text { Dzebic (2013) (test 1) } \\
\text { Combined survey and isovists }\end{array}$ & $\sqrt{ }$ & $\mathrm{O}$ & - & $\sqrt{ }$ & $\begin{array}{l}\text { Positive and neutral findings: "Isovist area was significantly positively correlated with } \\
\text { ratings of spaciousness [..] and clarity [as well as with] pleasantness [...] and beauty" } \\
\text { (19). "Number of vertices was positively correlated with ratings of complexity [... and] } \\
\text { interestingness [...] but was not significantly correlated to ratings of pleasantness" } \\
\text { (18) }\end{array}$ \\
\hline $\begin{array}{l}\text { Dzebic (2013) (test 2) } \\
\text { Combined survey and isovists }\end{array}$ & $\mathrm{O}$ & $\mathrm{O}$ & - & $\mathrm{O}$ & 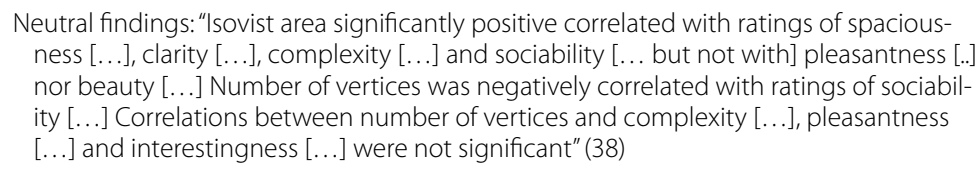 \\
\hline $\begin{array}{l}\text { Ostwald and Dawes (2013) } \\
\text { Isovist analysis }\end{array}$ & $\mathrm{O}$ & - & $x$ & - & $\begin{array}{l}\text { Neutral and contrary findings: the results for isovist area show that "four of the houses } \\
\text { possess a lower level of prospect at the point of entry and a higher level at the centre } \\
\text { of the living room [... however,] this trend would be anticipated in any family house } \\
\text { large enough to have a separate entry and living room [...] There is no overarching } \\
\text { pattern in the results for mystery found in the five paths" (155). "There are insufficient } \\
\text { similarities [in paths of five of Frank Lloyd Wright's canonical Prairie houses] to sup- } \\
\text { port the claim that there are any underlying spatio-visual patterns" (156) }\end{array}$ \\
\hline
\end{tabular}

Dawes and Ostwald (2014a) $\quad 0 \quad 0 \quad 0 \quad 0 \quad$ Neutral findings: partial support for factors of prospect and refuge: "of the ten primary Isovist analysis indicators, nine support the hypothesis, and of the ten secondary, seven support the hypothesised condition [... However, when] calculating the Pearson's correlation coefficient for each combination of prospect and refuge [...] four of the [... five of Wright's textile-block houses] show at least one strong positive correlation [... as well as] at least one negative [... and] six are moderate" (238). "Wright's preferred technique of reduplicating prospect and refuge characteristics was manipulation of ceiling height and distance to a solid surface" (238). Levels of mystery and complexity are confirmed to decrease in three of five cases. "In total, 26 out of 35 primary indicators [...] supported the presence of the four major measurable properties of the Wright Space" (239)

Dawes and Ostwald (2014b) _ $\quad \mathrm{O} \quad \ldots \quad$ _ $\quad \mathrm{O} \quad$ - $\quad$ Neutral findings: limited evidence for spatial pattern in five of Wright's Usonian houses: Isovist analysis

pattern for prospect supported by isovist area results (80\%) while "longest radial data decreased in $60 \%$ of cases" (17). More limited evidence for mystery with results for "proportional occlusivity [that] show a significant pattern of decreasing in every house" [while actual occlusivity levels vary]" (17). Results for mystery show that only "60\% of the paths conformed to either [... drift direction or drift magnitude and] only two houses conformed to both conditions" (18)

Dawes and Ostwald (2014c)

\section{(18)}

Isovist analysis

(imilarity between 17 of Wright's most famous houses. Refuge values for three positions in living room (threshold, centre and hearth) most similar as "the minimum radial line results are identical under both window conditions [opaque or transparent, which] confirms that window conditions alone will not alter the spatial experience recorded by the isovists" (11)

Vaughan and Ostwald (2014)

Contrary findings: "the fractal analysis results [...] generally fall marginally along the exterior section of the path [...] before rising [...] along the interior section [...]" (564). The first part of this result is relatively neutral, but overall this is contrary to the anticipated result

\begin{tabular}{lllll} 
Supportive $\sqrt{ }$ & 10 & 2 & 2 & 6 \\
Neutral $O$ & 8 & 12 & 4 & 4 \\
Contrary $X$ & 1 & 3 & 2 & 1 \\
\hline
\end{tabular}

$\sqrt{ }$ supportive, $O$ neutral, $X$ contrary, - not considered in the study, $P$ prospect, $R$ refuge, $M$ mystery, $C$ complexity

a Views on nature and built environment from two rooms

b Views on nature from a room and outdoors

Another criterion which is accepted as playing a significant role in interior preference is complexity. Twelve out of the total of thirty-four studies consider complexity, of which all but one, are in the interior category. Six studies confirm Hildebrand's argument for the importance of visual complexity in spatial preference, which makes complexity (after prospect) the second most relevant criterion for interior settings. Two surveys
(Scott 1993a, b) confirm a preference for "interiors that offer more rather than less complexity" (Scott 1993b, p 31 ). Four tests that use combined approaches suggest a relationship between complexity and spaces which are aesthetically pleasing or interesting. These have been categorised as "supportive" results for the purposes of this paper (Franz et al. 2004; Wiener et al. 2007; Dzebic 2013). Four other combined approaches present 


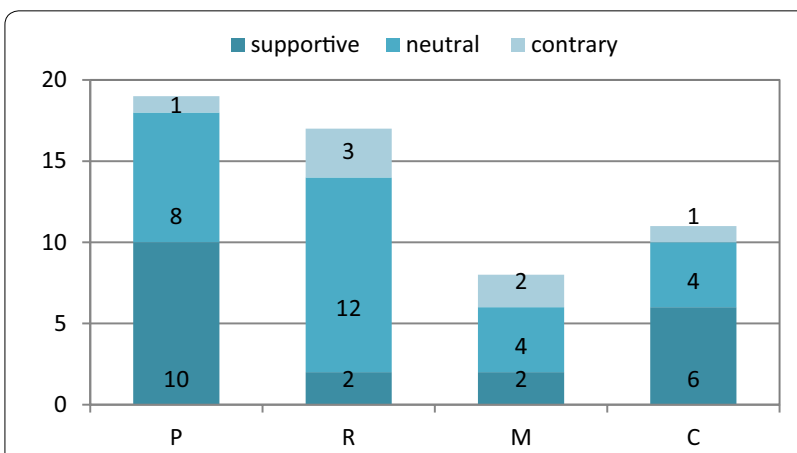

Fig. 3 Findings of studies into the impact of prospect, refuge, mystery and complexity in interiors

relatively neutral findings which relate, for example, to measured properties of supposedly complex spaces. For example, Dawes and Ostwald (2014b) examine five of Frank Lloyd Wright's Usonian houses using seven isovist measures. Their data provides only limited evidence in support of Hildebrand's version of prospect-refuge theory as for each measure at least one house presented values directly contrary to Hildebrand's assumptions. Only proportional occlusivity was supportive, as an indicator for mystery, "which might form the basis of a more sophisticated measure of the seen and un-seen properties of a design" (Dawes and Ostwald 2014b, p 19). This is an interesting finding because, as with many modern interiors, Wright's houses consist of a series of visually connected, open-planned rooms, a property that allegedly works to evoke a sense of mystery.

Whereas the majority of the computational studies used isovists, there is one exception, a study which used fractal dimensions to examine the experience of visual complexity in Wright's Robie House (Vaughan and Ostwald 2014). Hildebrand's argument, drawing on prospect-refuge theory, is that the path from the road to the entrance and then to the living room in the Robie House commences with a higher degree of visual complexity and mystery and ends with a lower level. Data developed by Vaughan and Ostwald (2014) shows that Hildebrand's argument is marginally true for the exterior section of the path, but the findings are strongly contrary for the interior.

\section{Discussion}

Altogether, findings of thirty-four studies are summarised in this paper of which three are related to urban environments, ten examine landscapes and twenty-one investigate interiors. Most of the studies involving landscapes and urban environments were conducted in the 1980s and 1990s (eight out of thirteen) while interior studies were generally more recent, including all of the mathematical-computational studies or those using combined approaches (Fig. 4).

While acknowledging that the veracity of each set of results is most strongly pertinent within its venue grouping, considering the complete set of results is also informative. With thirty-six supported results for factors, thirty-four neutral and twelve contrary, the evidence is mixed. The complete set of results (Table 4) shows that the most examined characteristic is, not surprisingly, prospect (38\%), and it is also the most confirmed (53\%). Prospect is a dominant topic of testing especially in interior studies where it is excluded in only two out of twenty-one tests, and it is also the lead factor tested in landscape studies. Refuge, an indicator for safety and privacy, is the second most supported factor $(22 \%)$ but it has the highest rate of both neutral ( $41 \%)$ and contrary findings $(41.5 \%)$. Prospect has the second highest percentage of all neutral findings ( $29 \%$ ) of which most belong to the results for interiors (8 out of 10). Certainly, very few studies present results that are completely contrary (14\%), of which most reject, as just indicated, refuge (41.5\%), followed by mystery (33\%) and then prospect $(17 \%)$ and complexity (8.5\%) (Fig. 5). Mystery and complexity are the least examined characteristics $(14.5 \%$ each) and have been tested predominantly in interior settings. Within its category, complexity has more supportive results (six) than neutral (five) or contrary (one) (Fig. 6). In total, when examining the results of all of the thirty-four studies holistically in this way, there are not enough supportive findings to emphatically substantiate prospect-refuge theory.

If the results are divided by venue, then the most supportive findings associated with prospect are related to interior venues (Fig. 7). Nine out of twenty-one studies confirm that wide, open rooms are perceived as more comfortable than enclosed ones. Curiously, only one of these interior studies presents a preference for a balance of openness and enclosure, while in landscape studies three out of ten confirm a preference for balanced settings. According to Scott (1993a), "people like vertically and horizontally expansive settings that are subdivided into smaller spatial zones" (13), a result that also confirms a need for enclosure in interiors. Originally, Appleton (1975) proposed that environments which offer a balance of both outlook and enclosure would be most preferred. In a later revision he advises that in many cases a "balance $[. .$.$] can be achieved from serial vision, involving the$ successive experiences of exposure to strongly contrasting landscape types, strong prospect and then strong refuge, is more potent than that which comes from trying to achieve a balance all at once" (Appleton 1984, p 102). This suggestion, which was developed to describe landscape preference, may also relate to the experience of 

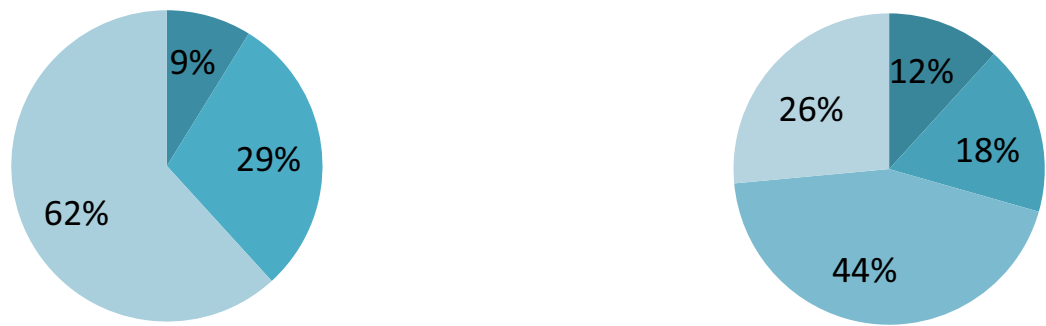

Fig. 4 The thirty-four studies divided by (1) venue and (2) decade when the research was conducted

interiors, as appealing designs were often composed of large, clearly open and smaller, enclosed spaces rather than offering both in one room. Perhaps because of this uncertainty, if there is need for enclosure or not, refuge is the least supported characteristic within the interior group (and also overall) with twelve (out of seventeen) neutral findings.

A preference for complexity has been confirmed by four interior studies which used combined approaches. Also, two survey-based studies confirm a preference for spaces that have more complex geometry (Scott 1993a, b). In addition, a second test also presents a preference for spaces that permit internal views and which offer natural content and daylight. Altogether, this is the only

Table 4 Findings relating to environmental preference summarised for all venues

\begin{tabular}{lrrrrr}
\hline Number of studies that are & P & R & M & C & SUM \\
\hline Supportive $\sqrt{ }$ & 19 & 8 & 3 & 6 & 36 \\
Neutral O & 10 & 14 & 5 & 5 & 34 \\
Contrary X & 2 & 5 & 4 & 1 & 12 \\
SUM & 31 & 27 & 12 & 12 &
\end{tabular}

$P$ prospect, $R$ refuge, $M$ mystery, $C$ complexity study in the entire set that confirms the importance of all four factors (Scott 1993a).

In order to further interpret the results of the present meta-analysis, it is useful to examine some features of the past research in more detail and begin to tabulate some considerations for developing future studies which will avoid the flaws present in some of the past research and fill important gaps in the field. Six categories of considerations are identified and discussed hereafter, being summarised in Table 5.

It is notable, when considering the studies compiled and examined here, that the majority of the survey results involved relatively small numbers of participants. Only eight of the 29 studies engaged 100 or more participants while 16 studies relied on responses of 20 or less participants. That such small studies remain widely cited as evidence of the efficacy of prospect-refuge theory is concerning. Furthermore, the larger studies tended to have more neutral results, leading to additional concerns about the usefulness of some past research (Nasar et al. 1983; Kaplan and Herbert 1988; Nasar 1988; Loewen et al. 1993). To further interpret the results, the demographic data associated with survey participants can be considered. For example, only six studies recruited

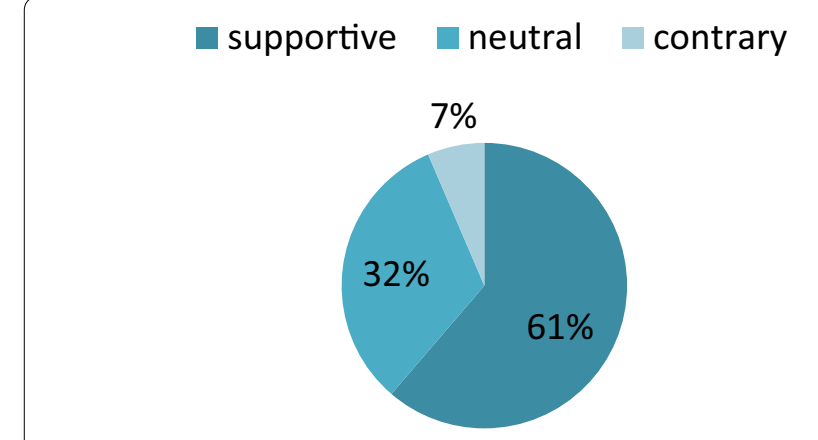

supportive neutral contrary

Fig. 5 Findings for (1) prospect and (2) refuge by all venues

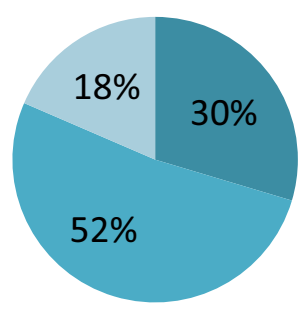




\section{supportive neutral contrary}

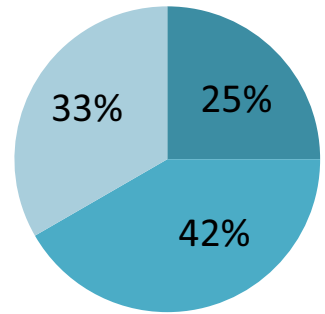

supportive neutral contrary

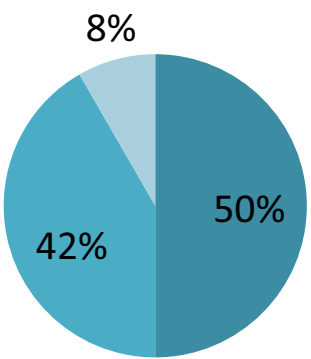

Fig. 6 Findings for (1) mystery and (2) complexity by all venues

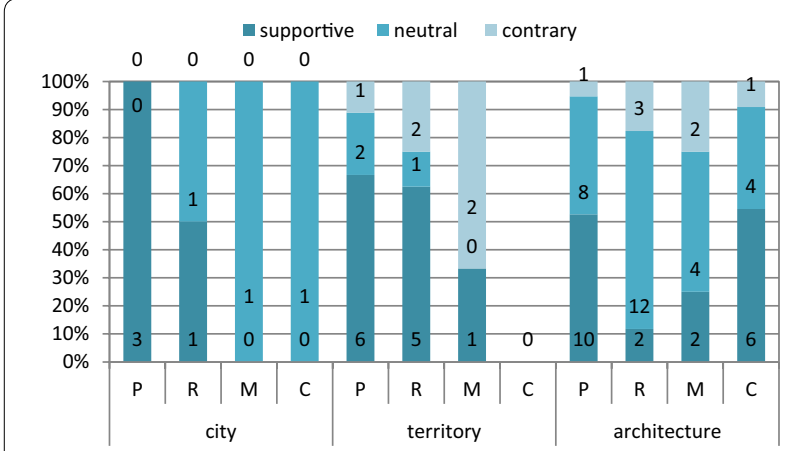

Fig. 7 Findings divided by venue and factor (prospect, refuge, mystery and complexity)

participants of varying background and ages whereas most of the studies relied on surveys of university students. Two studies (Conrad 1993) engaged participants who were trained in design as well as others who had no training in design to compare their responses, while another two studies explicitly selected only participants that were untrained (Scott 1993a, b). Only two studies developed a cross-cultural comparison, however, one of these was of participants from North-America and Australia; groups with relatively similar living conditions and cultural values (Nasar 1988; Kaplan and Herbert 1988). Furthermore-with one exception (Nasar 1988)-most of the studies are also of Western cultures. None of the studies considered the local background of participantsmeaning the area, for example, an urban, a suburban or rural environment, where a participant has predominantly lived-which may have a strong influence on spatial preference.

Problematically, in terms of research design, some of the stimuli sets used for surveys did not possess clear or carefully calibrated or graduated differences. Controlled

Table 5 Methodological issues raised in past research and future responses

\begin{tabular}{|c|c|c|}
\hline Theme & Issue & Future research \\
\hline Scale & $\begin{array}{l}\text { Too many of the empirical studies in this field rely on small }(<20) \\
\text { groups of participants. This leads to a lack of statistical significance }\end{array}$ & $\begin{array}{l}\text { Larger, more statistically rigorous studies are required to } \\
\text { methodically investigate these issues }\end{array}$ \\
\hline Homogeneity & $\begin{array}{l}\text { There is a strong tendency for the survey participants in past research } \\
\text { in this field to be young (18-21 year old) university students who } \\
\text { have grown up in middle class Western environments }\end{array}$ & $\begin{array}{l}\text { A greater diversity of survey participants (age, gender, } \\
\text { race, background, ethnicity and culture) is needed to } \\
\text { methodically investigate these issues }\end{array}$ \\
\hline $\begin{array}{l}\text { Influence of encultura- } \\
\text { tion and advantage }\end{array}$ & $\begin{array}{l}\text { It is rare for any information to be collected about survey participants' I } \\
\text { level of education, social opportunities or economic status. All of } \\
\text { these factors potentially have an impact on the interpretation of the } \\
\text { results }\end{array}$ & $\begin{array}{l}\text { Information of this type should be collected to enable } \\
\text { the results to be cross-referenced to social, economic } \\
\text { and educational status }\end{array}$ \\
\hline Background venues & $\begin{array}{l}\text { Relatively few past studies present a detailed rationale for the 'views' } \\
\text { (venue backdrops) chosen. Those views are typically treated as } \\
\text { incidental to the research, but this has not yet been proven }\end{array}$ & $\begin{array}{l}\text { A study should be undertaken which varies venue } \\
\text { backdrops and/or backdrops and foregrounds, but } \\
\text { without varying the geometry of the setting. This will } \\
\text { provide deeper insights into the impact of the venue }\end{array}$ \\
\hline Graduated stimuli & $\begin{array}{l}\text { In past research there is a lack of consideration of the nature and } \\
\text { gradation of stimuli }\end{array}$ & $\begin{array}{l}\text { Stimuli design should be carefully graduated (in terms } \\
\text { of their changing characteristics) to provide a higher } \\
\text { quality of information about the relationship between } \\
\text { space and environmental preference }\end{array}$ \\
\hline $\begin{array}{l}\text { Correlation of empirical } \\
\text { and mathematical data }\end{array}$ & $\begin{array}{l}\text { The relationships between human perceptions and spatial geometry } \\
\text { a have only been partially established, leading to several difficulties } \\
\text { relating empirical and computational results }\end{array}$ & $\begin{array}{l}\text { There is a need for more research which rigorously } \\
\text { correlates human perceptions and preferences with } \\
\text { environmental geometry (isovists and fractals) }\end{array}$ \\
\hline
\end{tabular}


changes of one or more variables are necessary in stimuli when accuracy is required, and most of the more recent studies test virtual environments, which allow such controlled variations. However, few of the early studies used such controlled conditions, leading to difficulties replicating or understanding their results. This is a problem because some studies have shown that the background of a stimuli can have a significant influence on the ratings of an image (Stamps 2008a, b).

Overall, only a few studies produced statistically thorough results and analysis. Interestingly, some of these were undertaken by the same researcher and contradict his own previous findings, thereby demonstrating the difficulty of producing an emphatic outcome. For example, Stamps (2008a) finds that an increase of refuge is associated with an increase of feelings of comfort, but his following study presents contrary results (2008b). Also one of the interior studies that used a combined approach contradicts an earlier finding as isovist area (openness) did not correlate any more with the rated factor of beauty but only with spaciousness, complexity and sociability (Dzebic 2013). Another (neutrally categorised) finding is unexpected, as more complex spaces (which can be related to a low isovist-area-to-perimeter ratio) seem to allow a higher recognition rate of words and images that had to be memorised in such complex interiors while the area (large or small) made no difference on such ratings (Dalton et al. 2010).

Significantly, many of the studies that have been categorised as neutral are based on mathematical or computational analysis of interiors testing more than one measure. This often leads to discrepancies in their results. So far, there is no clear determination of which measures are the most relevant, but there are assumptions that, for example, in isovist analysis (which twelve of the interior studies use), ratios or proportional values relate better to spatial dimensions than pure measures (Dawes and Ostwald 2014a, b). Such works are part of the recent trend to examine prospect-refuge theory mathematically or in a combined approach with survey methods and computational analysis. However, there is still need to refine these new research methods by implementing clear, controlled changes and seeking more detailed correlations between human perceptions and spatio-geometric measures.

\section{Conclusions}

Despite what seems to be widespread acceptance in the architectural, urban and landscape design fields, the quantitative evidence for prospect-refuge theory remains inconsistent. It is especially problematic that the results which are most commonly cited in architecture relate to studies of natural environments, not interiors or urban environments. As this paper demonstrates, the results are most valid in specific venues. For example, the benefits of a close visual connection to nature and of inhabiting a space that offers both an open area for outlook and a more private area for being hidden, have been broadly supported by past research in natural settings. However, the same spatio-visual configuration (the same volume of outlook and enclosure) in an interior overlooking a city skyline, will trigger a different psychological reaction. In particular, enclosure appears to be primarily significant in natural and urban settings. These two results are especially challenging for architectural arguments about the need for prospect and refuge, as the evidence for the latter is far weaker than for the former, and especially so for interiors. More specifically for designers, the results for complexity seem to confirm that a degree of complexity in interior space is preferred, but they are unclear about how much or where it should be. The results for mystery are less emphatic ( $75 \%$ neutral or negative) although few of the spaces tested in these studies appear to possess a high level of mystery. Moreover, very few of the hypothesised triggers for mystery have ever been examined using quantitative means. For example, visual connections, changing levels of light and varying ceiling heights (Hildebrand 1991, 1999) have been claimed to be significant components of preferred spaces, but only two of the studies examined here consider them and both are neutral in their findings.

Of equal importance to the meta-analysis and results contained in this paper is their implications for future research. As identified in the previous discussion section (Table 5), there are clear messages in this paper about the type of research that is needed to clarify the conflicting messages found in past studies, and fill substantial gaps in our knowledge. In particular, future research should test in more detail which degree of prospect and refuge and also mystery would be perceived as comfortable in a natural or an urban context. Additional criteria including daylight, illumination and the venue itself-for example, is it a relatively safe area, is it a crime-intense area or are there any other hazards? - would need to be considered. Also, the relevance of refuge in such a context would be interesting to examine. Which degree of prospect and refuge would achieve aesthetic quality in a natural or urban setting? Furthermore, it might be wise to test interiors that depict habitable space and which consist of more than one room, as previous studies considered mostly external views from one room but not so often internal view connections between spaces. This may change the results for refuge as well as for mystery and may identify a need for both.

Ultimately, the gaps in environmental preference research for architects, urban and landscape designers are both significant and largely unacknowledged outside 
small groups or researchers. For professionals and students, prospect-refuge theory seems to offer a simple explanation or formula for creating space, even though, as this paper demonstrates, the unanswered questions are more significant than the answered ones, or alternatively that the unknowns far exceed the knowns. These gaps have to be closed if designers are to use evidence-based strategies to shape our landscapes, cities and buildings.

\section{Authors' contributions}

Both authors have jointly developed the content, argument and writing for this paper. Both authors read and approved the final manuscript.

\section{Competing interests}

The authors declare that they have no competing interests.

Received: 24 November 2015 Accepted: 8 April 2016

Published online: 04 May 2016

\section{References}

Appleton J (1975/1996) The experience of landscape, rev edn. Wiley, London Appleton J (1984) Prospects and refuges re-visited. Landscape J. 3(2):91-103. Reprinted: Appleton J (1988) Prospects and refuges re-visited. In: Nasar $J L$ (ed) environmental aesthetics: theory, research and applications. Cambridge University Press, Cambridge, pp 27-44

Berlyne DE (1951) Attention, perception and behaviour theory. Psychol Rev 58(2):137-146

Conrad J (1993) Prospect/refuge theory: an experimental approach. Unpublished Master's Thesis, Queensland University of Technology, Brisbane

Crankshaw N (2008) Creating vibrant public spaces: streetscape design in commercial and historic districts. Island Press, Washington

Dalton S, Marshall P, Conroy-Dalton R (2010) Measuring environments for public displays: a space syntax approach. In: CHI'10, Atlanta, pp 3841-3846

Dawes MJ, Ostwald MJ (2014a) Spatio-visual patterns in architecture: an analysis of living rooms in Frank Lloyd Wright's houses. In: Madeo F, Schnabel MA (eds) Across: architectural research through to practice: 48th international conference of the architectural science association. Genova University Press, Genova, pp 151-162

Dawes MJ, Ostwald MJ (2014b) Testing the 'Wright Space': using isovists to analyse prospect-refuge characteristics in Usonian architecture. J Archit. doi:10.1080/13602365.2014.965722

Dawes MJ, Ostwald MJ (2014c) Prospect-refuge theory and the textileblock houses of Frank Lloyd Wright: an analysis of spatio-visual characteristics using isovists. Build Environ 80:228-240. doi:10.1016/j. buildenv.2014.05.026

Dosen AS, Ostwald MJ (2013a) Prospect and refuge theory: constructing a critical definition for architecture and design. Int J Design Soc 6(1):9-24

Dosen AS, Ostwald MJ (2013b) Methodological characteristics of research testing prospect-refuge theory: a comparative analysis. Archit Sci Rev 56(3):232-241. doi:10.1080/00038628.2013.809689

Dzebic V (2013) Isovist analysis as a tool for comparing responses towards the built environment. Master's thesis, University of Waterloo. http://hdl. handle.net/10012/7511

Ellard C (2009) You are here: why we can find our way to the moon, but get lost in the mall. Anchor Books, New York

Ellard C (2015) Places of the heart: The psychogeography of everyday life. Bellevue Literary Press, New York

Franz G, von der Heyde M, Bülthoff HH (2003) An empirical approach to the experience of architectural space in VR: Exploring relations between features and affective appraisals of rectangular interiors. In: digital design, 22nd eCAADe Conference, Graz

Franz G, von der Heyde M, Bülthoff HH (2004) Predicting experiential qualities of architecture by its spatial properties. In: Proceedings of the 18th IAPSConference, Vienna
Gallagher W (2007) House Thinking. Harper Perennial, New York Gutman R (ed) (2009) People and buildings. Transaction, London

Hagerhall CM (2000) Clustering predictors of landscape preference in the traditional Swedish cultural landscape: prospect-refuge, mystery, age and management. J Environ Psychol 20(1):83-90

Heerwagen J (1998) Design, productivity and well being: what are the links? In: the american institute of architects conference on highly effective facilities, Cincinnati, March 12-14

Heerwagen J (2008) Psychological value of space. National institute of building sciences. http://www.wbdg.org/resources/psychspace_value.php. Accessed 22 Jun 2015

Heerwagen J, Orians G (1993) Humans, habitats and aesthetics. In: Kellert SR, Wilson EO (eds) The biophilia hypothesis. Island Press, Shearwater Books, Washington, pp 138-172

Hildebrand G (1991) The wright space: pattern and meaning in Frank Lloyd wright's houses. University of Washington Press, Seattle

Hildebrand G (1999) Origins of architectural pleasure. University of California Press, Berkeley

Husserl E (1973/1913) Logical Investigations. Findlay JN, trans., Routledge, London. Originally published in German: (1900) Logische Untersuchungen. 1, Prolegomena

Jacobsen M, Silverstein M, Winslow B (2002) Pattern of home: the ten essentials of enduring design. Tuanton Press, Newtown

Kaplan S (1987) Aesthetics, affect, and cognition: environmental preference from an evolutionary perspective. Environ Behav 19(1):3-32

Kaplan R, Herbert EJ (1988) Familiarity and preference: a cross-cultural analysis. In: Nasar JL (ed) Environmental aesthetics. Cambridge University Press, Cambridge

Kaplan R, Kaplan S (1989) The experience of nature: a psychological perspective. Cambridge University Press, Cambridge

Kellert SR (2005) Building for life: designing and understanding the humannature connection. Island Press, Washington

Kruft HW (1994) A history of architectural theory from vitruvius to the present. Princeton Architectural Press, New York

Kuo F, Sullivan W (2001) Environment and crime in the inner city: does vegetation reduce crime? Environ Behav 33:343-367

Lidwell W, Holden K, Butler J (2003) Universal principals of design. Rockport Publishers, Beverley

Lippmann PC (2010) Evidence-based design of elementary and secondary schools: a responsive approach to creating learning environments. Wiley, New York

Loewen LJ, Steel GD, Suedfeld P (1993) Perceived safety from crime in the urban environment. J Environ Psychol 13(4):323-331

Menin S (2003) Constructing place: mind and the matter of place-making. Routledge, London

Mumcu S, Düzenli T, Özbilen A (2010) Prospect and refuge as the predictors of preferences for seating areas. Scientific Res Essays 5(11):1223-1233

Nasar JL (1988) Visual preferences in urban street scenes: a cross-cultural comparison between Japan and the United States. In: Nasar JL (ed) Environmental aesthetics: theory, research and applications. Cambridge University Press, Cambridge, pp 260-274

Nasar JL, Julian D, Buchman S, Humphreys D, Mrohaly M (1983) The emotional quality of scenes and observation points: a look at prospect and refuge. Landscape Plan 10(4):355-361

Nettleton B (1987) Parks for children: some perspectives on design. Landscape Australia 3(87):244-248

Ostwald MJ, Dawes MJ (2013) Using isovists to analyse architecture: methodological considerations and new approaches. Int J Constr Environ 3(1):85-106

Perloff HS (2015) The quality of the urban environment: essays on "new resources" in an urban age. Routledge, London

Roberts JW (2003) Prospect-refuge theory and alvaar Aalto's experimental house at Muuratsalo. In: progress: the proceedings of the twentieth annual conference of the society of architectural historians (SAHANZ), Sydney

Ruddell EJ, Hammitt WE (1987) Prospect refuge theory: a psychological orientation for edge effect in recreation environments. J Leisur Res 19(4):249-260

Scott SC (1993a) Visual attributes related to preference in interior environments. J Inter Design Educ Res 18(1\&2):7-16 
Scott SC (1993b) Complexity and mystery as predictors of interior preferences. J Inter Design 19(1):25-33

Shaftoe H (2008) Convivial urban spaces: creating effective public places. Earthscan, London

Stamps AE (2006) Interior prospect and refuge. Percept Mot Skills 103(3):643-653

Stamps AE (2008a) Some findings on prospect and refuge theory: I. Percept Mot Skills 106(4):147-162

Stamps AE (2008b) Some findings on prospect and refuge theory: Il. Percept Mot Skills 107(1):141-158

Ulrich R (1984) View through a window may influence recovery from surgery. Science 224:420-421

Ulrich R (1993) Biophilia, biophobia, and natural landscapes. In: Kellert SK, Wilson EO (eds) The biophilia hypothesis. Island Press, Shearwater Books, Washington, pp 78-137
Unwin S (2010) Twenty buildings every architect should understand. Routledge, London

Vaughan J, Ostwald MJ (2014) Quantifying the changing visual experience of architecture: combining movement with visual complexity. In: Madeo F, Schnabel MA (eds) Across: architectural research through to practice: 48th international conference of the architectural science association. Genova University Press, Genova, pp 557-568

Wiener J, Franz G, Rossmanith N, Reichelt H, Bülthoff H (2007) Isovists analysis captures properties of space relevant for locomotion and experience. Perception 36:1066-1083

Wohlwill JF (1976) Environmental aesthetics: the environment as a source of affect. In: Altman I, Wohlwill JF (eds) Human behavior and environment. Plenum, New York, pp 37-86

\section{Submit your manuscript to a SpringerOpen ${ }^{\circ}$ journal and benefit from:}

- Convenient online submission

- Rigorous peer review

- Immediate publication on acceptance

- Open access: articles freely available online

- High visibility within the field

- Retaining the copyright to your article 